\title{
The Phase of Supernormal Excitation in Relation to the Strength of Subthreshold Stimuli
}

\author{
Masayoshi Yokoyama, M.D.
}

\section{Summary}

The presence of supernormal excitation was confirmed repeatedly in all 10 cases following cardiac surgery.

By the stimulation of minimum subthreshold impulses capable of originating ventricular responses, the supernormal excitation was limited only at the descending limb of $T$ wave. The duration lasted only 0.02 sec at the minimum subthreshold stimuli.

But the higher subthreshold stimuli produced the longer duration of supernormal excitation phase. The duration of the excitation phase prolonged towards the following $\mathrm{R}$ wave, hardly extending towards the preceding $R$ wave, with the increase of subthreshold stimuli.

\section{Additional Indexing Words:}

Supernormal excitation Supernormal phase Subthreshold stimulus

\begin{abstract}
A supernormal period of excitability was reported in ventricular muscle A by Hoff and Nahum ${ }^{11}$ in 1938. The period occurred near the end of the relative refractory period, being coined to indicate that phase in the excitable cycle of the heart when electrical excitation could be produced by subthreshold stimuli.

Though the term "supernormal excitation" has some relations with "supernormal conduction", ${ }^{2)}$ only the former was discussed in this paper, being distinguished from the latter for convenience' sake.

In heart surgery, temporary pacemaker electrodes were routinely attached on the right ventricle before closure of the chest wall. On measurements of ventricular stimulation threshold by using temporary pacemaker electrodes, the supernormal excitation was often demonstrated by subthreshold impulses.

A review of literatures showed the variable duration of supernormal phase. Schamroth and Friedberg' ${ }^{3)}$ mentioned that it was a brief interval of $0.02 \mathrm{sec}$. Hernandez-Pieretti et $\mathrm{al}^{4)}$ reported that its duration in man
\end{abstract}

From the Heart Institute of Japan, Tokyo Women's Medical College, 10 Kawadacho, Shinjukuku, Tokyo, Japan.

Received for publication June 19, 1975. 
ranged from 0.16 to $0.20 \mathrm{sec}$. More recently Spear and Moore ${ }^{2)}$ described that the period lasted approximately for $0.09 \mathrm{sec}$ in a Purkinje fiber.

In this paper, the author confirmed that the duration of the supernormal excitation phase was related to the strength of subthreshold stimuli. ${ }^{5)}$

The phase of the supernormal excitation was only limited at the end of $T$ wave when the heart was stimulated by the minimum subthreshold stimuli capable of evoking ventricular response, but the phase prolonged towards the following $R$ wave as the increase of subthreshold stimuli.

\section{Methods}

Ten patients ( 5 males and 5 females), ranging in age between 3 and 33 years old (average 11), were operated upon under diagnoses of heart disease (Table I). Their postoperative courses were satisfactory without any complications. Regular sinus rhythm was maintained throughout present investigations. No medications such as procainamide, isoproterenol, propranolol etc were given.

Three temporary pacemaker electrodes (Flexon ${ }^{\circledR}$ 2597-63, Davis \& Geck American Cyanamid) were employed in each case. The leads were stainless steel and teflon coated. Only the tip of an electrode was not insulated by a teflon collar. Two of 3 electrodes were attached on the anterior right ventricular myocardium for the use of ventricular stimulation. The third was placed subcutaneously as an indifferent lead.

Two myocardial electrodes were sutured in different ways as shown in Fig. 1. The tip of the A electrode was completely berried in the heart muscle. The B electrode possessed the naked tip of $1.0 \mathrm{~cm}$ in length outside the epicardial surface.

Both $\mathrm{A}$ and $\mathrm{B}$ electrodes were placed in myocardium by half thickness of the ventricular wall in depth and $1.0 \mathrm{~cm}$ in length. The purpose of the B electrode was aimed to obtain high stimulation threshold after development of tissue adhesions

Table I

\begin{tabular}{c|c|c|c}
\hline Case No. & Age (years) & Sex & Diagnosis \\
\hline 1 & 17 & F & ASD \\
2 & 6 & F & VSD \\
3 & 32 & M & MS \\
4 & 33 & M & MS \\
5 & 3 & M & T/F \\
6 & 5 & M & T/F \\
7 & 4 & F & VSD \\
8 & 4 & F & VSD \\
9 & 3 & M & ASD \\
10 & 3 & F & ASD \\
F (female), M (male), ASD (atrial scptal defect), VSD (ventric- \\
ular septal defect), MS (mitral stenosis), T/F (tetralogy of Fallot)
\end{tabular}


A.

B.

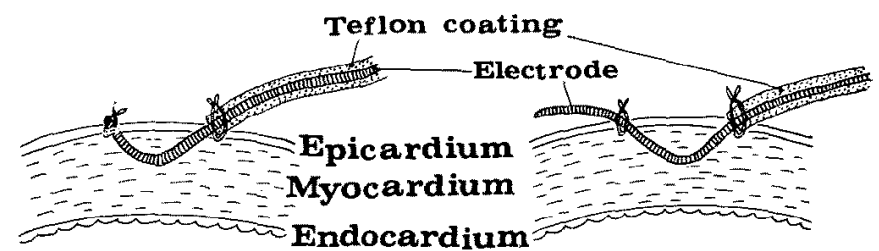

Fig. 1. Two myocardial pacing electrodes were attached on the anterior right ventricular wall by 2 different ways, $A$ and $B$. The $B$ electrode was mainly employed for present studies of supernormal excitation because it showed higher stimulation threshold. The A electrode was just for reservation.

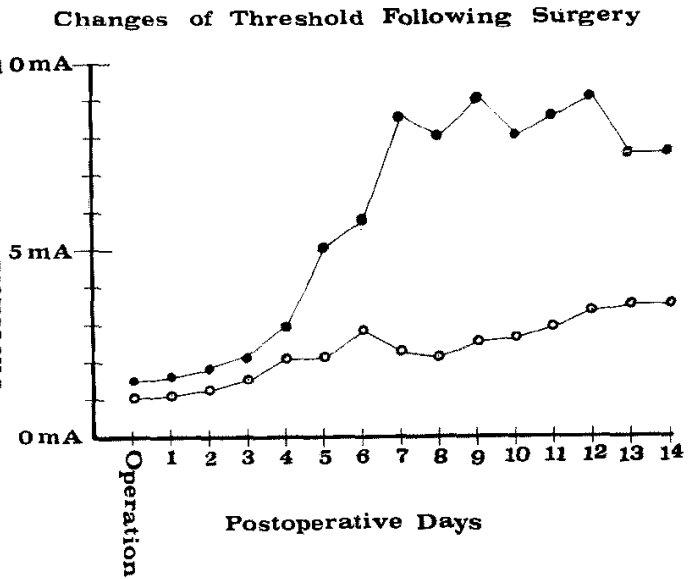

Fig. 2. Daily changes of ventricular stimulation threshold were evaluated.

- indicates thresholds measured by the B electrode of Fig. 1. The threshold started increasing on the fourth postoperative day. $O$ indicates thresholds examined by the A electrode of Fig. 1, which remained relatively stationary.

around the naked part of electrodes because of the occurrence of electric current leakage from the lead tip to the surrounding non-myocardial tissue. The purpose of the A electrode was just for reservation though it had a lower stimulation threshold.

The high stimulation threshold induced the wide range of subthreshold current capable of originating supernormal excitation, which made it easier to investigate the subthreshold phenomena. ${ }^{11}$

Preliminarily the difference between postoperative myocardial stimulation thresholds measured by the A and by the B electrodes (Fig. 1) was studied in several postoperative cases. The threshold difference was very slight right after surgery, while in a few days the threshold examined by the $B$ electrode started increasing (Fig. 2). In present series, the myocardial B lead was connected to the cathodal 
terminal, and the subcutaneous indifferent lead to the anodal terminal.

All stimuli were delivered by utilizing Medtronic Model $5880 \mathrm{~A}$, the pulse width of which was $1.8 \pm 0.2$ msec. Those stimuli were square wave.

In the presence of sinus rhythm, the stimulus from the extrinsic pacemaker, thrown into the ventricle at the set cycle, might occur at any instant during the sinus cycle. Although there was a theoretic danger that stimuli from artificial pacemakers might induce severe ventricular arrhythmias, experience had demonstrated repeatedly that there was no practical danger. Electrical current delivered was $10 \mathrm{~mA}$ at most.

Present studies of supernormal excitation were performed on the first, on the third and most intensively on the fifth postoperative day.

Examinations were carried out in the morning, during which patients were tried to be as relaxed as possible.

For measurements of stimulation thresholds, the fixed rate of the extrinsic pacemaker was preset faster than the patient's ventricular rate (Table II) and the pacing current was gradually reduced whilst continuously watching ECG. The value at which no more heart stimulations occurred was noted. The threshold value was determined as the lowest effective impulse current.

Then the phenomenon of supernormal excitation was carefully examined. The subthreshold pacing current was reduced step by step until the disappearance of the supernormal excitation. At each current, 3 min recordings were obtained. The paper speed of $50 \mathrm{~mm}$ per second was preferred to the ordinary paper speed of $25 \mathrm{~mm}$ per second.

A change in the rate of the electrical pacemaker impulses did not alter the time interval between a spontaneous ventricular complex and one produced by the electrical pacemaker. ${ }^{6)}$

Analysing the long strips of electrocardiograms as shown in Fig. 3, the relationship of subthreshold pacemaker stimuli with the duration of supernormal excitation phase was investigated. Both the onset and its end of the supernormal phase of excitation were taken as the earliest and the latest point where the subthreshold

Table II

\begin{tabular}{c|c|c|c|c|c}
\hline $\begin{array}{c}\text { Case } \\
\text { No. }\end{array}$ & $\begin{array}{c}\text { Patient's } \\
\text { Ventricular } \\
\text { Rate/min }\end{array}$ & $\begin{array}{c}\text { Pacing } \\
\text { Rate/min }\end{array}$ & $\begin{array}{c}\text { Shortest } \\
\text { Interval of } \\
\text { Q-effectual } \\
\text { Spike (sec) }\end{array}$ & $\begin{array}{c}\text { Forward Prolongation of } \\
\text { Excitation Phase with the } \\
\text { Increase of Subthreshold } \\
\text { Stimuli (sec) }\end{array}$ & $\begin{array}{c}\text { Ventricular } \\
\text { Stimulation } \\
\text { Threshold } \\
\text { (mA) }\end{array}$ \\
\hline 1 & 80 & 100 & 0.30 & 0 & 4.0 \\
2 & 125 & 150 & 0.28 & 0.02 & 5.8 \\
3 & 74 & 100 & 0.30 & 0.02 & 4.1 \\
4 & 107 & 110 & 0.24 & 0 & 3.8 \\
5 & 120 & 140 & 0.28 & 0.02 & 4.0 \\
6 & 120 & 150 & 0.26 & 0.02 & 4.8 \\
7 & 105 & 150 & 0.26 & 0 & 2.1 \\
8 & 135 & 150 & 0.26 & 0 & 5.8 \\
9 & 140 & 150 & 0.26 & 0 & 3.4
\end{tabular}




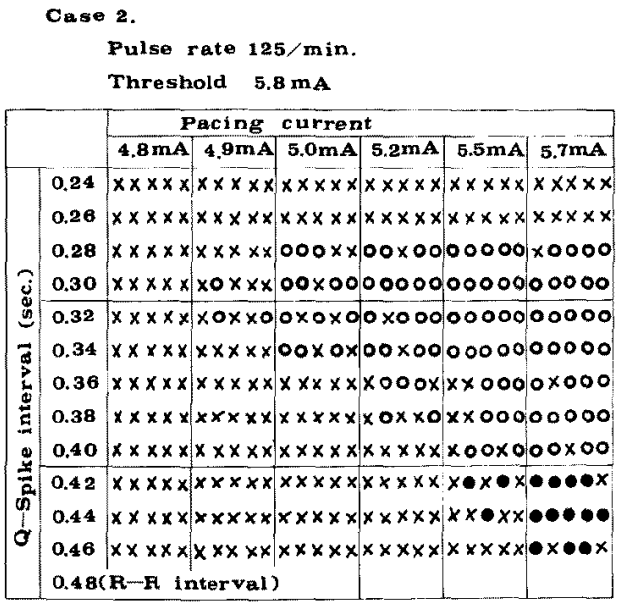

Fig. 3. $x$ : not pacing $O$ : pacing 0 : fusion beat

Pacemaker stimuli of $4.9 \mathrm{~mA}$ falling between 0.30 and $0.32 \mathrm{sec}$ after the onset of the QRS were followed by a response. With the increase of strength of subthreshold pacing stimuli, the duration of the supernormal excitation phase prolonged towards the following $R$ wave.

pacemaker stimulus would cause ventricular depolarization. Timing of events was measured from the beginning of the preceding QRS complex.

\section{RESULTS}

1. The relation between the ventricular stimulation threshold and the minimum subthreshold current capable of evoking supernormal excitation was studied. The range of subthreshold current capable of evoking the ventricular response was related to the value of ventricular stimulation threshold.

When the ventricular stimulation threshold was low, the subthreshold current range capable of evoking supernormal excitation was very narrow. In cases with high stimulation threshold, on the contrary, the phenomenon of supernormal excitation was found in the wide range of subthreshold current.

The subthreshold current range capable of originating supernormal excitation was pictured in Fig. 4, which existed between the stimulation threshold current and about 10-15\% less current than that. Subthreshold current range was very narrow below the $1.0 \mathrm{~mA}$ of stimulation threshold, resulting in difficulty to find the phenomenon.

2. The shortest interval of Q-effectual spike ranged between 0.24 and $0.36 \mathrm{sec}$, averaging in $0.29 \mathrm{sec}$ in our 10 cases. The average pulse rate was $110 / \mathrm{min}$. The relation of the pulse rate with the shortest Q-effectual spike interval was not detected among these 10 cases. It was observed, however, 


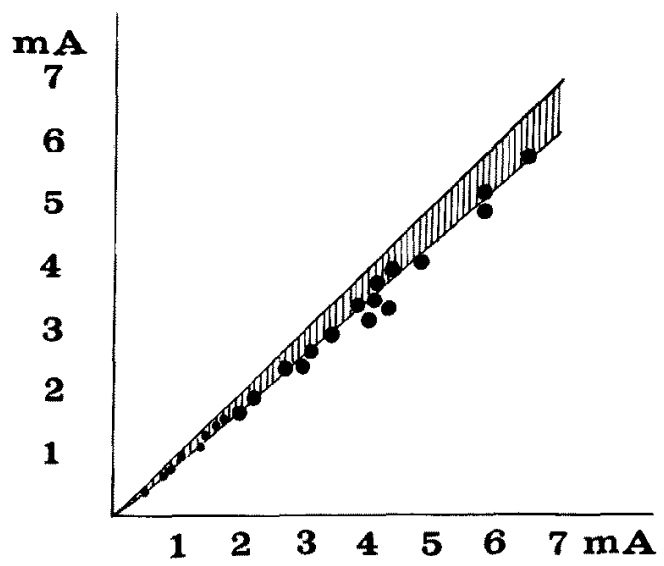

Fig. 4. The area of longitudinal lines indicates a current range in which subthreshold stimuli are capable of originating a ventricular response.

- is the minimum subthreshold stimuli capable of evoking the ventricular contraction. The supernormal excitation is easily found in cases with higher stimulation threshold.

in a particular case (Case 3) in which the pulse rate reduced from $120 / \mathrm{min}$ to $74 / \mathrm{min}$ in several postoperative days. The shortest interval of Q-effectual spike was $0.24 \mathrm{sec}$ at the pulse rate of $120 / \mathrm{min}$. It prolonged to 0.26 and $0.30 \mathrm{sec}$ at the pulse rate of 100 and $74 / \mathrm{min}$ respectively. That was, the decrease of pulse rate was followed by the prolongation of the shortest Q-effectual spike interval.

By falling the fixed rate $(50 / \mathrm{min})$ stimuli above the threshold value, the period of refractory period could be determined. In our all cases, the shortest interval of Q-effectual spike was almost equal to the refractory period. The earliest effectual response was at boundary of refractory period.

3. The minimum subthreshold impulses cable of evoking ventricular response occurred during a very short critical period after a $Q R S$ complex. In 8 of 10 cases, the duration of supernormal excitation phase by the minimum subthreshold stimuli lasted only $0.02 \mathrm{sec}$ (Figs. 3 and 5). Other 2 cases (Cases 6 and 8 ) had the time span of $0.04 \mathrm{sec}$, the reason of which was explained by low ventricular excitation threshold in these 2. Not every minimum subthreshold stimulus occurring during this critical period produced manifest electrical excitation. The incidence of ventricular excitation was low at the minimum subthreshold current even if stimuli fell during the limited period (Fig. 3).

4. The duration of supernormal excitation phase and the strength of subthreshold stimuli. In all cases, the duration of the excitation phase prolonged towards the following $R$ wave in stepwise with the increase of sub- 


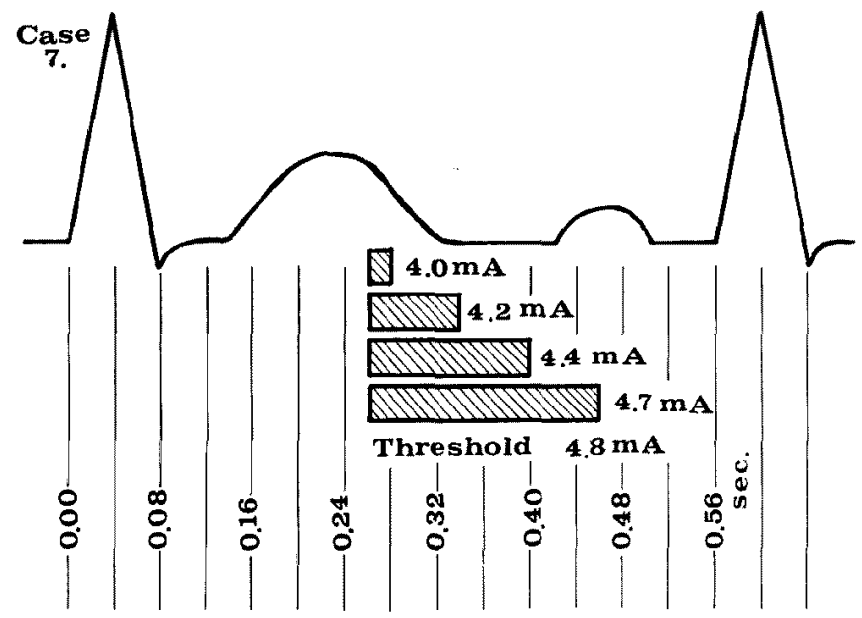

Fig. 5. The minimum current necessary to elicit ventricular excitation was $4.0 \mathrm{~mA}$.

The phase was noted between 0.26 and $0.28 \mathrm{sec}$ after the QRS complex. The phase extended only towards the following $R$ wave with the increase of subthreshold stimuli. At stimuli of $4.7 \mathrm{~mA}$, the excitation was observed between 0.26 and $0.46 \mathrm{sec}$ with the duration of $0.20 \mathrm{sec}$.

threshold stimuli. For example, in Case 7 (Fig. 5), at the minimum subthreshold spike potential of $4.0 \mathrm{~mA}$, pacemaker captures occurred only when it fell 0.26 to $0.28 \mathrm{sec}$ after the preceding QRS depolarization. By the higher subthreshold stimuli, this duration prolonged towards the following $R$ wave. By the use of $4.7 \mathrm{~mA}$ stimuli, the phase of ventricular excitation was detected between 0.26 to $0.46 \mathrm{sec}$ after the beginning of the QRS complexes, with a duration of $0.20 \mathrm{sec}$. The phase hardly extended towards the preceding $R$ wave, but only towards the following $\mathrm{R}$ wave in all cases. Four of our present 10 cases showed the slight prolongation towards the preceding $R$ wave, but the time of forward prolongation was no more than $0.02 \mathrm{sec}$ in all. The rest of 6 cases did not show any forward prolongation (Table II).

5. Supernormal excitation and pacing rhythm. In 9 of 10 cases, the phase of supernormal excitation prolonged step by step as the increase of subthreshold stimulation current. And finally the duration of the phase was observed from the descending limb of $T$ wave to the following $P$ wave. By the current just below the stimulation threshold, the phase almost occupied the whole diastolic phase. Fusion beat appeared when the pacing spike fell near the following $\mathrm{P}$ wave (Fig. 3).

Only in Case 4, the increase of subthreshold stimuli was followed by pacing phase (Fig. 6).

The diastolic excitability of the ventricular muscle was considered almost 
constant in literatures, $\left.{ }^{2}\right)$ but our observations suggested the later phase of diastole was more stable as pictured in Fig. 7.

6. QRS delay from the stimulus. Donara and Cammilli" found the difference of QRS delay from the stimulus. The earliest effective stimulus to

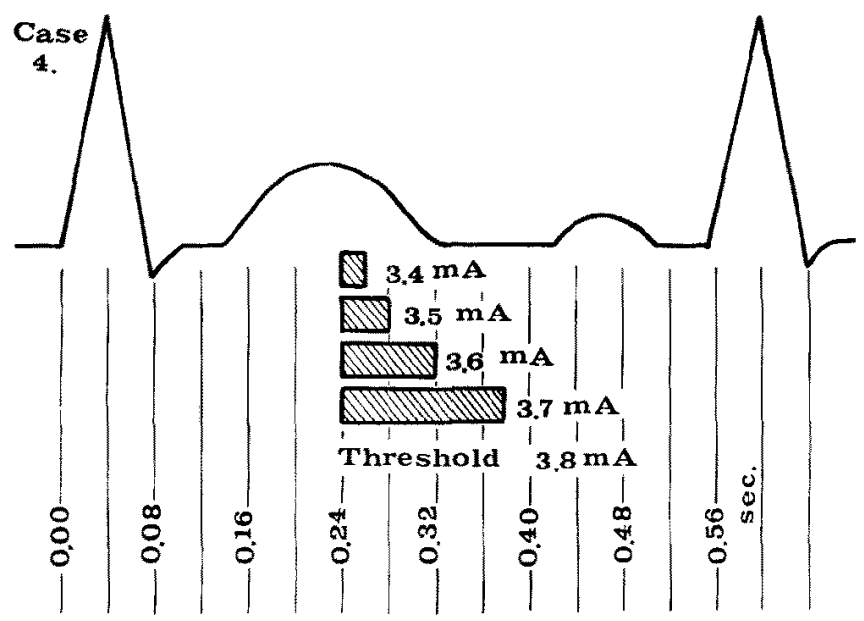

Fig. 6. At the stimulation of $3.7 \mathrm{~mA}$, the supernormal excitation was between 0.24 to $0.38 \mathrm{sec}$ with the duration of $0.14 \mathrm{sec}$, but next to $3.7 \mathrm{~mA}$, pacing rhythm was obtained. Thus, the maximum duration of supernormal excitation phase was only $0.14 \mathrm{sec}$ in this case, which was exceptional in our series.

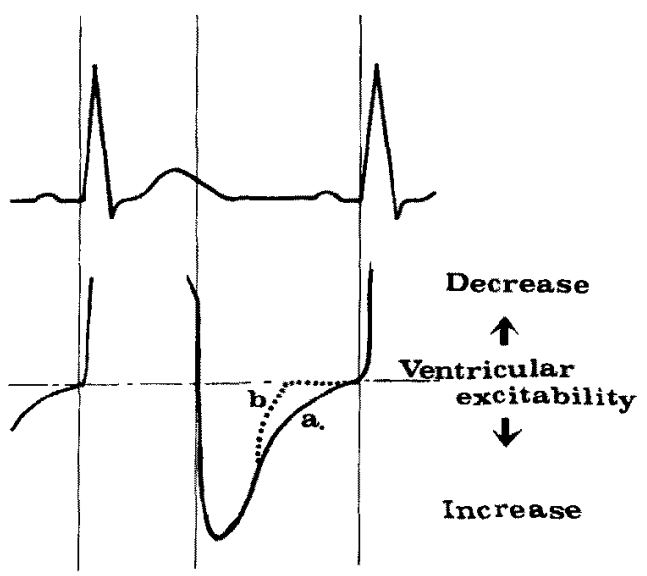

Fig. 7. Schematic drawing of ventricular excitability of the diastolic phase.

The excitability is most increased at the early diastolic phase, and gradually reduced as shown by line a. The Case 4 of Fig. 6 seemed to follow the dotted line $b$. 


\section{Case 2.}

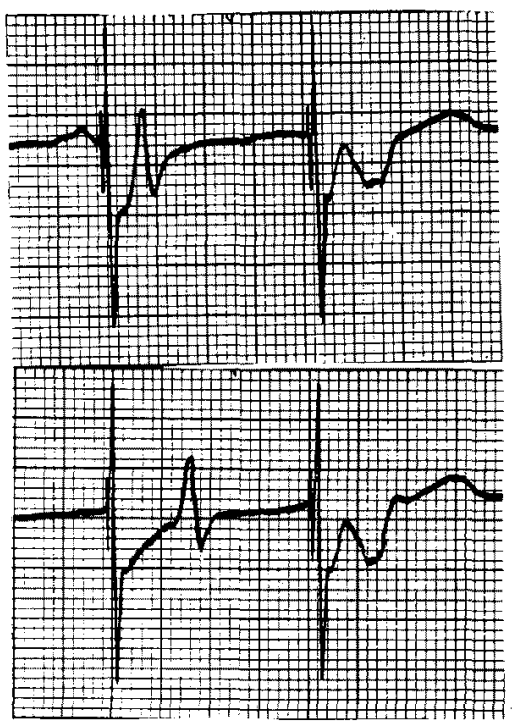

\section{$50 \mathrm{~mm} / \mathrm{sec}$.}

Fig. 8. The QRS delay of supernormal excitation is constant whether the excitation is elicited far (upper tracing) or near (lower tracing) from the patient's QRS complex.

QRS delay was $0.02 \mathrm{sec}$, and the latest one had $0.01 \mathrm{sec}$ delay in their case.

In our present series, however, a delay in the ventricular response to the external stimulation was constant throughout the supernormal phase (Fig. 8).

\section{Discussion}

The phenomenon of supernormal excitability has been observed in literatures by 2 different stimulation methods. The first is to observe the contraction of the whole ventricle following the myocardial stimulation as in our studies. The second is to record transmembrane action potentials following intracellular stimulation. ${ }^{2), 8), 9}$ It is difficult to conclude whether the 2 supernormal excitations observed by different ways are exactly same phenomenon. The electrical supernormality demonstrated in a particular cell by the use of a microelectrode should be more fundamental phenomenon. The ventricular contraction induced by surface stimulation would be influenced upon by various factors besides the clcctrical impulse itself.

However, the supernormality frequently seen in patients with exhausting artificial implanted pacemakers $\left.{ }^{3}, 10\right)$ is more similar in fashion to that induced 
by surface stimulation as in our studies.

It became clear from present investigations that the period of supernormal excitation so far believed to be very limited only at the descending branch of $T$ wave was truly observed when the heart was stimulated by the minimum subthreshold current capable of evoking the ventricular response. If the ventricle was stimulated by impulses just below the stimulation threshold, the supernormal excitation phase was not limited at the descending limb of $T$ wave, but existing with long duration from the end of the preceding $T$ wave to the following $R$ wave.

The relation between the duration of the supernormal phase and the strength of subthreshold stimuli had been noticed by Soloff and Fewell ${ }^{6}$ in 1960, and by Hernandez-Pieretti et $\mathrm{al}^{4)}$ in 1969 , but any precise descriptions were not given. Soloff et al showed that the minimal current strength capable of originating a response in a patient with an epicardial electrode was $2.6 \mathrm{~mA}$, and excitation then occurred within $0.04 \mathrm{sec}$ after the peak of the $T$ wave. When the current was increased to $7.0 \mathrm{~mA}$, ventricular excitation occurred within $0.02 \mathrm{sec}$ after the peak of the $T$ wave and also in the PR segment.

In spite of the opinion that this phase did not exist in the normal human heart, ${ }^{11)}$ the author concluded that the supernormal phase judged from the whole ventricular contraction would exist under entirely normal myocardial conditions as our all cases showed phenomena repeatedly.

Spear et $a^{2)}$ demonstrated recently by utilizing intracellular stimulation and recording transmembrane action potential that the phenomenon was found throughout the left and right bundle branch Purkinje system but not in the His bundle or in ventricular muscle.

Feldman ${ }^{12)}$ found no supernormal period in patients with a catheter electrode pacemaker. This was probably due to the low threshold and narrow range of subthreshold current capable of originating the phenomenon.

The explanation of the mechanism of this supernormality is not certain. Massumi et al $^{13)}$ described that the period of supernormal excitation was due to negative afterpotentials. According to the research by Spear et $\mathrm{al}^{2)}$ the period of supernormal excitation began during phase 3 at full repolarization, and they concluded that the supernormality resulted partly because, during the latter phase of repolarization, the threshold potential had recovered more completely than had the membrane potential. The membrane potential had to undergo a smaller degree of additional depolarization to reach threshold potential, and this depolarization could be brought about by a weaker depolarizing current. 


\section{REFERENCES}

1. Hoff HE, Nahum LH: Supernormal phase in the mammalian ventricle. Am J Physiol 124: 591,1938

2. Spear JF, Moore EN: Supernormal excitability and conduction in the His-Purkinje system of the dog. Circulat Res 35: 782, 1974

3. Schamroth L, Friedberg HD: Wedensky facilitation and the Wedensky effect during high grade A-V block in the human heart. Am J Cardiol 23: 893, 1969

4. Hernandez-Pieretti O, Morales-Rocha J, Barcelo JE: Supernormal phase of conduction in human heart demonstrated by subthreshold pacemakers. Brit Heart J 31: 553, 1969

5. Yokoyama M: Supernormal excitation. Shinzo (Heart) 6: 1403, 1974 (in Japanese)

6. Soloff LA, Fewell JW: Supernormal phase of ventricular excitation in man. Its bearing on the genesis of ventricular premature systoles, and a note on atrioventricular condition. Am Heart J 59: 869, 1960

7. Dolara A, Cammilli L: Supernormal excitation and conduction. Electrocardiographic observation during subthreshold stimulation in two patients with implanted pacemaker. Am J Cardiol 21 : 746, 1968

8) Weidmann S: The effects of calcium ions and local anesthetics on electrical properties of Purkinje fibers. J Physiol 129: 568, 1955

9. Hoshi $T$, Matsuda K: Excitability cycle of cardiac muscle examined by intracellular stimulation. Jap J Physiol 12: 433, 1962

10. Linenthal AJ, Zoll PM, Blumgart HL: Quantitative studies of ventricular refractory and supernormal periods in man. Trans Ass Am Physicians 75: 285, 1962

11. Brooks CM, Hoffman BF, Suckling EE, Orias O: Excitability of the Heart. Grune \& Stratton, New York, p75, 1955

12. Feldman DS: Excitability of the human heart on endocardial stimulation. Clin Res 11: 166,1963

13) Massumi RA, Amsterdam EA, Mason DT: Phenomenon of supernormality in the human heart. Circulation 46: 264, 1972 